\title{
Teias de um Observatório para a saúde das populações do campo, da floresta e das águas no Brasil
}

\author{
Webs of an Observatory monitoring health of peasants, \\ river dwellers and forest populations in Brazil
}

\section{Telas de un Observatorio para la salud de la población del campo, de los bosques y del agua en Brasil}

\author{
Fernando Ferreira CARNEIRO ${ }^{1}$ \\ Vanira Matos PESSOA ${ }^{2}$ \\ Carlos André Moura ARRUDA ${ }^{3}$ \\ Cleber Adriano Rodrigues FOLGADO ${ }^{4}$ \\ Rackynelly Alves Sarmento SOARES 5 \\ Rosana $\mathrm{KIRSCH}^{6}$ \\ Alan Freihof TYGEL ${ }^{7}$ \\ Priscila Delgado de CARVALHO ${ }^{8}$
}

\section{RESUMO}

APolítica Nacional de Saúde Integral das Populações do Campo, da Floresta e das Águas reconhece a dívida histórica do Estado brasileiro com a saúde dessas populações, apresenta a necessidade de superação do modelo de desenvolvimento econômico e social na busca de relações homemnatureza responsáveis e promotoras da saúde. Como fruto da implantação dessa política, pensando no seu monitoramento e avaliação, estruturou-se em 2012 um Observatório denominado OBTEIA. Objetiva-se apresentar a experiência desse Observatório, focando o seu processo metodológico e nos principais resultados. Este Observatório vem sendo estruturado a partir da criação de uma Teia de Saberes e Práticas, que envolve movimentos sociais, academia e gestoras(es)/trabalhadoras(es) do Sistema Único de Saúde. O foco das ações tem sido o de visibilizar essa população por meio

1 Professor Adjunto. Departamento de Saúde Coletiva, Universidade de Brasília (UnB). Endereço: Faculdade de Ciências da Saúde, Campus Darcy Ribeiro - Asa Norte. CEP 70910900 - Brasília, DF - Brasil. E-mail: fernandocarneiro. brasilia@gmail.com

2 Pesquisadora em Saúde Pública. Fundação Oswaldo Cruz (FIOCRUZ), Ceará. E-mail: vanirapessoa@gmail.com

3 Professor Adjunto I. Faculdade de Ensino e Cultura do Ceará (FAECE). E-mail: andrecaninde@yahoo.com.br

4 Graduando em Direito (UEFS) e Dirigente do MPA/Via Campesina. E-mail: folgadompa@gmail.com

5 Pesquisadora do Núcleo de Estudos em Saúde Pública (NESP), Universidade de Brasília(UnB). E-mail: rackynelly@ unb.br

6 Socióloga, integrante da EITA - Cooperativa de Trabalho Educação, Informação e Tecnologia para Autogestão E-mail: necakirsch@gmail.com

7 Doutorando da Pós-Graduação em Informática da UFRJ e integrante da EITA - Cooperativa de Trabalho Educação, Informação e Tecnologia para Autogestão. E-mail: alantygel@gmail.com

8 Doutoranda em Ciência Política na Universidade Federal de Minas Gerais. Mestre pelo Instituto de Ciência Política da Universidade de Brasília, com pesquisa sobre a presença da sociedade civil do Brasil e do Paraguai na Reunião Especializada sobre Agricultura Familiar, do Mercosul. E-mail: prisciladcarvalho@gmail.com 
de um portal interativo na internet (www.saudecampofloresta.unb.br), coleta e processamento de informações, notícias, estudos, vídeos, cadernos, bem como promover o debate acerca de referenciais críticos e métodos de pesquisa coerentes com o modo de viver dessas populações. Essa experiência vem possibilitando o envolvimento de distintos grupos e seu reconhecimento político dessa ferramenta como estratégia de fortalecimento e melhoria da produção de informações capazes de disparar ações e decisões focadas nas populações do campo, da floresta e das águas.

Palavras-chave: sistema único de saúde; saúde da população rural; políticas públicas.

\section{ABSTRACT}

The National Policy on Comprehensive Health of Populations in Rural recognizes the historical debt of the Brazilian State with the health of these populations, presents the need to overcome the economic and social development model in the search for responsible man-nature relations that promote health. As a result of implementation of this policy, aiming its monitoring and evaluation, an observatory -called OBTEIA - was created in 2012. This paper aims to present the experience of the Observatory, focusing its methodological process and the main results. It has been built around a Web of Knowledge and Practices, which involves social movements, academy and managers / workers of the Unified Health System. The focus of action has been to visualize this population through an interactive portal on the Internet (www.saudecampofloresta.unb.br), collection and processing of information, news, studies, videos, books. Besides, it promotes debates about referential and critical research methods consistent with the way of life of these populations. This experience has enabled the involvement and political recognition of distinct groups, and became a strategy to strengthen and improve the production of information able to trigger actions and decisions for populations of field, forest and water.

Keywords: unified health system; rural health; public policies.

\section{RESUMEN}

La Política Nacional de Salud Integral de las Poblaciones del Campo, de los Bosques y de las Águas reconoce la deuda histórica del Estado brasileño con la salud de estas poblaciones y presenta la necesidad de superación del modelo de desarrollo económico y social en la búsqueda de relaciones hombre-naturaleza responsables y promotoras de la salud. Como resultado de la implementación de esta política, pensando en su monitoreo y evaluación, se estructuró en 2012 un observatorio llamado OBTEIA. El objetivo es presentar la experiencia de este Observatorio, centrando en su proceso metodológico y en los principales resultados. Este Observatorio viene estructurandose a partir de la creación de una Red de Saberes y Practicas, que involucra movimientos sociales, academia y gestores / trabajadoras(es) del Sistema Único de Salud. El foco de las acciones ha sido lo de visibilizar esta población por medio de un portal interactivo en la Internet (www.saudecampofloresta.unb. $\underline{b r}$ ), que recoge y procesa informaciones, noticias, videos, cuadernos, bien como facilita el debate 
acerca de referenciales críticos y métodos de investigación coherentes con el modo de vivir de estas poblaciones. Esta experiencia viene posibilitando el involucramiento y reconocimiento político de distintos grupos, de esta herramienta como estrategia de fortalecimiento y mejoría de la producción de informaciones capaz de desencadenar acciones y decisiones centradas en las poblaciones del campo, del bosque y de las aguas.

Palabras clave: sistema único de salud; salud de la población rural; políticas públicas.

\section{INTRODUÇÃO}

O Brasil vive um momento histórico marcado por lutas por direitos sociais básicos. Multidões de pessoas de todo o país saíram às ruas reivindicando acesso a serviços públicos de qualidade, principalmente, o transporte, a saúde e a educação. Dessa forma, a luta pelos direitos, nesse país, ainda é um desafio para as populações das cidades, principalmente em grandes metrópoles. Contudo, para as populações do campo, da floresta e das águas, residentes, em sua grande maioria, nas regiões do Norte e Nordeste do país, prevalecem situações de iniquidades, vulnerabilidade e desigualdades históricas e estruturais ainda mais graves, como falta de acesso aos serviços de saúde e ao saneamento.

Ainda, no século XXI, as populações mais invisíveis para as políticas públicas do Estado, são os(as) camponeses, populações atingidas por barragens, extrativistas, pescadores, ribeirinhos, quilombolas, indígenas, dentre outras. Dessa forma, torna-se fundamental visibilizar as necessidades de saúde dessas populações para que o Estado seja pressionado a planejar, agir e avaliar suas ações com vistas à garantia dos direitos de todos os cidadãos.

Como forma de garantir o que preconiza a Constituição Federal de 1988 na direção de se efetivar as lutas de redemocratização do país nessa década, foi criado um sistema único, público e universal, o Sistema Único de Saúde (SUS), tendo como princípios: universalidade, integralidade e equidade ${ }^{1}$. A fim de se garantir esses princípios e como forma de fortalecer o SUS, são formuladas políticas públicas específicas tendo como foco populações prioritárias. Somente em 2011 foi publicada a Política Nacional de Saúde Integral das Populações do Campo e da Floresta (PNSIPCF).

A PNSIPCF reconhece a dívida histórica do Estado brasileiro com a saúde das populações do campo, apresenta a necessidade de superação do modelo de desenvolvimento econômico e social na busca de relações homem-natureza responsáveis e promotoras da saúde e a extensão de ações e serviços de saúde que atendam às populações, respeitando suas especificidades. Essa política visa a promover a saúde das populações do campo e da floresta por meio de ações e iniciativas que reconheçam as especificidades de gênero, geração, raça/cor, etnia e orientação sexual, visando ao acesso aos serviços de saúde, à redução de riscos e agravos à saúde decorrentes dos processos de trabalho e das tecnologias agrícolas e à melhoria dos indicadores de saúde e da qualidade de vida ${ }^{2}$.

Essa política tem caráter transversal no SUS e necessita de articulação intersetorial para ser ISSN 1982-8829

Tempus, actas de saúde colet, Brasília, 8(2), 275-293, jun, 2014// 
efetivada com setores como: desenvolvimento agrário, meio ambiente, educação, pesca e aquicultura, dentre outros. Cabe-nos, ainda, enfatizar o protagonismo dos movimentos sociais na luta por sua elaboração, implementação, monitoramento e avaliação. Dentre esses citam-se: Articulação dos Povos Indígenas do Brasil (APIB); Comissão Pastoral da Terra (CPT); Coordenação Nacional de Articulação das Comunidades Negras Rurais Quilombolas (CONAQ); Confederação Nacional dos Trabalhadores na Agricultura (CONTAG); Conselho Nacional das Populações Extrativistas (CNS); Federação dos Trabalhadores na Agricultura Familiar (FETRAF); Movimento dos Atingidos por Barragens/Brasil (MAB); Movimento de Luta pela Terra (MLT); Movimento de Mulheres Camponesas (MMC); Movimento Nacional dos Pescadores (MONAPE); Movimento dos Pequenos Agricultores (MPA); Movimento dos Trabalhadores Rurais Sem Terra (MST); Mulheres Trabalhadoras Rurais - Movimento das Margaridas (MTRMM); Movimento Interestadual das Quebradeiras de Coco Babaçu (MIQCB); Movimento da Mulher Trabalhadora Rural do Nordeste (MMTR-NE); e Federação dos Pescadores do Estado de Alagoas (FEPEAL).

Um espaço instituído é o Grupo da Terra, no qual estão representados os movimentos sociais (citados acima), governo e instituições de ensino e pesquisa. Esse grupo participa da formulação, do monitoramento e da avaliação das ações referentes à implantação da PNSIPCF.

Como fruto da implantação dessa política, bem como pensando no seu monitoramento e avaliação, iniciou-se em 2012 a estruturação de um Observatório, aqui denominado OBTEIA. Esse tem como base a constituição de uma Teia de Saberes e Práticas, que envolve intelectuais engajados especialistas na temática, pesquisadores populares e lideranças dos movimentos sociais do campo, da floresta e águas, gestores/trabalhadores do SUS. Essa teia tem como pressupostos a cooperação e a solidariedade no sentido de manter um diálogo crítico e horizontal, aproximando distintos saberes em prol da luta pelo direito à saúde dessas populações.

Dessa forma, este manuscrito objetiva apresentar a experiência do OBTEIA focando o seu processo metodológico e os principais resultados.

\section{COMO A TEIA COMEÇA A SER TECIDA?}

Estamos desafiados a constituir um observatório que avalie a situação de saúde da população do campo, da floresta e das águas e como o SUS vem respondendo às necessidades de saúde dessa população. Dessa forma, citamos cinco desafios identificados no processo de implantação desse observatório:

1) Como avaliar essa política pública e contribuir para sua implantação por meio de uma perspectiva crítica e emancipatória?

2) Como visibilizar a situação de saúde de uma população invisivel pelos dados oficiais, que reside em regiões do país com diferentes aspectos históricos, sociais, ambientais, econômicos, culturais e políticos? 
3) Que referenciais teóricos críticos nos subsidiam nessa articulação e na constituição dessa Teia?

4) Como nós, pesquisadores engajados nesse campo, podemos articular o conhecimento e metodologias oriundos da saúde coletiva (epidemiologia; planejamento, gestão e avaliação em saúde; ciências sociais; saúde e ambiente e trabalho) com os saberes e práticas das populações do campo, da floresta e das águas?

5) Que metodologias participativas podem ser implementadas nesse observatório a fim de possibilitar o diálogo entre movimentos sociais, pesquisadores engajados e gestores/trabalhadores do SUS?

Apontaremos, nessa perspectiva, possíveis aproximações a essas perguntas a fim de descrever o processo vivido na implementação desse Observatório.

\section{1) Como avaliar essa política pública e contribuir para sua implantação por meio de uma perspectiva crítica e emancipatória?}

Entre os objetivos do OBTEIA também estão o de avaliar e construir indicadores, utilizar novos métodos de análise, desenvolver pesquisas quantitativas e qualitativas, e ser, sobretudo, uma ferramenta de lutas cotidianas para os movimentos sociais, acadêmicos e profissionais do SUS para a melhoria da saúde das populações do campo, floresta e águas.

Inaugurando uma nova forma de estruturar um Observatório, o OBTEIA possui três instâncias principais: um comitê gestor; uma equipe executiva e a teia de saberes e práticas. O comitê gestor, coordenado pela Universidade de Brasília (UnB), é composto por membros do Ministério da Saúde, pela Secretaria de Gestão Estratégica e Participativa (SGEP), e de outras secretarias com interesse na temática; três representantes dos movimentos sociais, membros do grupo da terra $\left(\mathrm{MMC}^{9}, \mathrm{MAB}^{10}\right.$, FETRAF $^{11}$ ) e a Fundação Oswaldo Cruz (FIOCRUZ). Tem como funções coordenar, articular, executar, acompanhar e mobilizar movimentos sociais na implantação do OBTEIA.

A equipe executiva é responsável por operacionalizar as atividades planejadas pelo projeto de implantação do OBTEIA. Essa equipe está constituída por representantes dos movimentos sociais e profissionais/pesquisadores na área de saúde coletiva referentes aos temas: políticas públicas; saúde do campo; saúde, ambiente e trabalho; saúde da família; epidemiologia; pesquisa qualitativa; ciências da informação e comunicação; geoprocessamento; jornalismo; e áudio e vídeo.

Cabe-nos destacar que a função dessa equipe é elaborar estudos de base empírica e documental (com dados secundários), bem como organizar e executar atividades conforme acordado nas instâncias do OBTEIA, tais como: oficinas e seminários para a constituição da Teia de Saberes e

9 Movimento das Mulheres Camponesas.

10 Mulheres Atingidas por Barragens.

11 Federação de Trabalhadores da Agricultura Familiar.

ISSN 1982-8829 Tempus, actas de saúde colet, Brasília, 8(2), 275-293, jun, 2014// 
Práticas, debates e discussão dos principais produtos previstos no projeto inicial de implantação do OBTEIA. Além disso, essa equipe operacionaliza, por meio de Termos de Referências, os produtos e ações previstos para o OBTEIA (feitura e alimentação periódica do portal; elaboração de vídeo; organização de um livro e caderno popular, entre outros).

A Teia de Saberes e Práticas está sendo tecida por meio da sensibilização/envolvimento de agentes sociais, representantes dos movimentos sociais e gestores/profissionais do SUS e pesquisadores nacionais e internacionais engajados na temática foco do OBTEIA e, também daqueles que trabalham com referenciais críticos que contribuam para a efetivação da produção do conhecimento na área da saúde do campo, da floresta e das águas, tais como: pesquisa qualitativa, ecologia de saberes, metodologias ativas, epistemologias críticas e emancipatórias, políticas públicas e daqueles que desenvolvem pesquisas em temas prioritários para essas populações, como o dos agrotóxicos.

Imaginamos que essa composição de agentes sociais e políticos engajados com a realidade vivida pelas populações, alvo deste artigo, articuladas no diálogo contínuo e sistemático desvelando e criando novas possibilidades de atuação na relação sociedade-Estado, conferindo visibilidade a esse processo para o conjunto da sociedade, possa trazer novos elementos constitutivos de respeito e valoração dessas populações e uma integração de novos saberes (por exemplo, desenvolvimento de metodologias avaliativas-participativas com enfoque qualitativo) que traga para dentro das políticas públicas um olhar diferenciado relativo ao que é saúde e o como produzir saúde nos territórios brasileiros, em especial, no campo, nas florestas e nas águas.

\section{2) Como visibilizar a situação de saúde de uma população invisível pelos dados oficiais, que} reside em regiões do país com diferentes aspectos históricos, sociais, ambientais, econômicos, culturais e políticos?

Como forma de visibilizar a situação de saúde dessa população e a fim de destacar a invisibilidade em dados institucionais, o OBTEIA priorizou as seguintes estratégias: a criação de um portal na internet (www.saudecampofloresta.unb.br), o desenvolvimento de pesquisas documentais (com enfoque quantitativo e qualitativo), pesquisas empíricas (participativas), a produção de notícias semanais e de um informe mensal (Matutando, disponível portal), organização de um livro, de um caderno popular e de um vídeo.

Para fins de descrição neste artigo detalharemos, a seguir, apenas a constituição do portal, tendo em vista que os demais produtos ditos anteriormente estão em processo de elaboração, com exceção dos principais resultados das pesquisas documentais que serão apresentados na sessão de "primeiros achados".

O OBTEIA adotou uma estratégia de estruturar e lançar um portal na internet para divulgar notícias, informações e dados que ajudem a visibilizar as condições de saúde de uma população que, no Brasil, apesar de numerosa, é quase invisível. 
O desenvolvimento do portal do OBTEIA na internet teve início na I Oficina da Teia de Saberes e Práticas, em maio de 2013. Nessa atividade, constituiu-se o Grupo do Portal, que contribuiu diretamente na elaboração desse espaço virtual. O Grupo foi ampliado durante a II Oficina da Teia, ocorrida em dezembro do mesmo ano, mantendo-se a composição com integrantes de movimentos sociais, acadêmicos engajados e os profissionais do SUS.

Há desafios em desenvolver uma ferramenta de forma participativa. Os/as integrantes do Grupo do Portal estão em diferentes estados e organizações, com dinâmicas muito distintas. Nesse sentido, momentos de trabalho presencial, como as Oficinas, são situações que permitem que os/as envolvidos no Grupo do Portal dediquem-se a analisar a ferramenta e a construam coletivamente. Nos períodos entre as Oficinas, há iniciativas de trabalho à distância, por e-mail e reuniões virtuais. No entanto, a participação por meio virtual é reduzida em relação à produção coletiva presencial. A despeito disso, os integrantes do grupo do Portal recebem de forma continuada sugestões de layout, notícias, indicativos de bibliografias para a biblioteca virtual, melhorias estruturais do portal, bem como produtos resultantes dos processos de pesquisas para realizar um trabalho de tradução que seja acessível para distintos públicos.

Esta área de tecnologia da informação do OBTEIA tem se dedicado a visibilizar dados abertos, que são bases de dados que estão dentro de sistemas do governo Federal, mas com difícil acesso. A perspectiva está em tornar a informação livre para circular, possibilitando que seja usada para embasar as reivindicações por melhores condições de saúde para as populações do campo, floresta e águas.

A criação do portal gerou uma nova possibilidade de busca na internet sobre informações de saúde dessas populações. Até seu lançamento, em setembro de 2013, ao realizar uma pesquisa web do termo "saúde do campo" localizava-se poucos documentos. A perspectiva da saúde do campo, floresta e águas, como proposta pelos movimentos sociais ainda não tinha um espaço específico na internet. A necessidade de ampliar o acesso à informação sobre saúde de campesinos, quilombolas, ribeirinhos, pescadores dentre outros, para além da perspectiva do rural, foi um dos avanços da criação do portal.

Focando na ampliação do acesso às informações sobre saúde do campo, floresta e águas, está em processo de elaboração, pelo portal, de uma janela que trará dados sobre aspectos econômicos e de saúde de municípios brasileiros. O objetivo será catalogar, por município da federação, a localização de dados e informações sobre saúde dessas populações para análises que o OBTEIA ou outros usuários, pesquisadores, profissionais/gestores, movimentos sociais desejem realizar.

3) Que referenciais teóricos críticos e que metodologias participativas podem ser implementadas nesse observatório a fim de possibilitar o diálogo entre movimentos sociais, pesquisadores engajados e gestores/trabalhadores do SUS?

Neste percurso, algumas dúvidas se colocam: a Ecologia de Saberes como conceito pode ISSN 1982-8829

Tempus, actas de saúde colet, Brasília, 8(2), 275-293, jun, 2014// 
aproximar ou não a academia dos movimentos sociais? Como apontar para a busca de soluções criativas frente aos problemas enfrentados e para a necessária superação dos elementos que separam as diversas iniciativas na busca por um outro modelo de sociedade, mais igualitária e justa? No momento em que o conhecimento acadêmico não se torna mais valorizado do que os saberes obtidos na luta popular, dão-se os primeiros passos para essa convergência.

Conceitos que apontam para uma produção compartilhada de saberes, como a Ecologia de Saberes e a Educação Popular, podem ser ferramentas de práxis na elaboração, sistematização e reconhecimento dos diversos conhecimentos presentes na população do campo, floresta e águas, apontando novas perspectivas para um diálogo mais horizontal entre o paradigma hegemônico e o paradigma emergente.

Assim, a Teia de Saberes e Práticas envolve os dois grupos acima, além de pesquisadores, militantes sociais e profissionais do SUS ligados à questão de saúde no campo, na floresta e nas águas envolvidos no processo e nos territórios de pesquisa.

A construção de uma Teia de Saberes e Práticas relaciona-se com as demandas históricas dos movimentos sociais, pois numa construção dessa natureza o conhecimento popular presente nas organizações de base não é descartado como inválido ou de menor valor. A Teia pressupõe um processo de diálogo entre os diversos tipos e formas de conhecimento de modo que o conjunto de conhecimentos diversos é reforçado, ampliado e resignificado.

Obviamente, nesse processo aparecem tensões, contradições, pontos de vista diferentes, que, em função dos marcos teóricos adotados, não precisam ser exterminados. O que se busca é a relação entre essas diferenças, compreendendo que diversidade não é sinônimo de fragmentação e, muito pelo contrário, pode vir a significar maior unidade e respeito a partir do reconhecimento das diferenças. Nesse processo de construção coletiva aponta-se, portanto, uma perspectiva emancipatória e de resignificação crítica do conjunto de conhecimento imposto - em determinados casos - pela ciência dita moderna.

Assim, a Teia de Saberes e Praticas constitui-se em elemento de práxis cotidiana do OBTEIA, no qual a ação concreta nos territórios é enriquecida pelos movimentos e pelo conjunto de sujeitos ativos do processo. É dessa forma que o conjunto de elementos desenvolvidos pelo OBTEIA ultrapassa os limites de sua ação apenas como observatório, mas inaugura uma relação de construção permanente de conhecimento, revisão crítica de conhecimentos já estabelecidos e ações concretas que nos territórios experimentam a relação entre teoria e prática, transformando-se mutuamente.

4) Como nós, pesquisadores engajados nesse campo, podemos articular o conhecimento e metodologias oriundos da saúde coletiva (epidemiologia; planejamento, gestão e avaliação em saúde; ciências sociais; saúde e ambiente e trabalho) com os saberes e práticas das populações do campo, da floresta e das águas? 
Nós temos exercitado em grupo a promoção do diálogo e debatido acerca de saberes e metodologias que dispomos, de maneira a apresentar resultados que representem os anseios dos movimentos sociais e formuladores das políticas públicas e pesquisadores. Temos construído um esforço coletivo de valorizar e reconhecer as potencialidades e os limites da ciência na aproximação com a realidade sem, contudo, desprezar o saber científico das diversas áreas do conhecimento e as interfaces desses com os saberes e práticas oriundos dos movimentos sociais e comunidades.

A partir do exposto, apresentamos, brevemente, como temos constituído os espaços das oficinas e reuniões do comitê gestor e equipe executiva para avançar na análise dos dados obtidos das fontes secundárias. Identificamos um volume de dados existentes em uma diversidade de bases que não são articuladas entre si. Estamos produzindo, a partir dessa identificação, a sistematização desses dados, gerando informações que ainda são insuficientes e incompletas, se compararmos às disponíveis para a população urbana. Novas formas de disponibilização dessa informação estão sendo discutidas para facilitar a sua análise pelos movimentos sociais e atores do SUS.

Adiantamos a seguir os primeiros resultados dessas pesquisas documentais:

a) O que os números nos falam acerca da população do campo, da floresta e das águas?

Atualmente, no Brasil, temos 190.755 .799 pessoas residentes, sendo 160.925 .804 na zona urbana e 29.829.995 na zona rural, ou seja, 15,6\% da população brasileira vive em áreas rurais

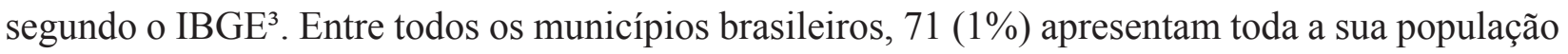
residindo em domicílio urbano. Em 3.875 (70\%) municípios a população residente em área urbana é superior à rural. Em apenas 1.619 (29\%) municípios a população residente em domicílio rural supera o urbano (Ver Figura 1). Entre esses, 759 (47\%) encontram-se na região Nordeste, 418 (26\%) na região Sul, 214 (13\%) na região Sudeste, 144 (9\%) estão localizados na região Norte e 84 (5\%) na região Centro-oeste. 
Figura 01: Distribuição percentual da população residente por situação do domicílio rural - Brasil - 2010.
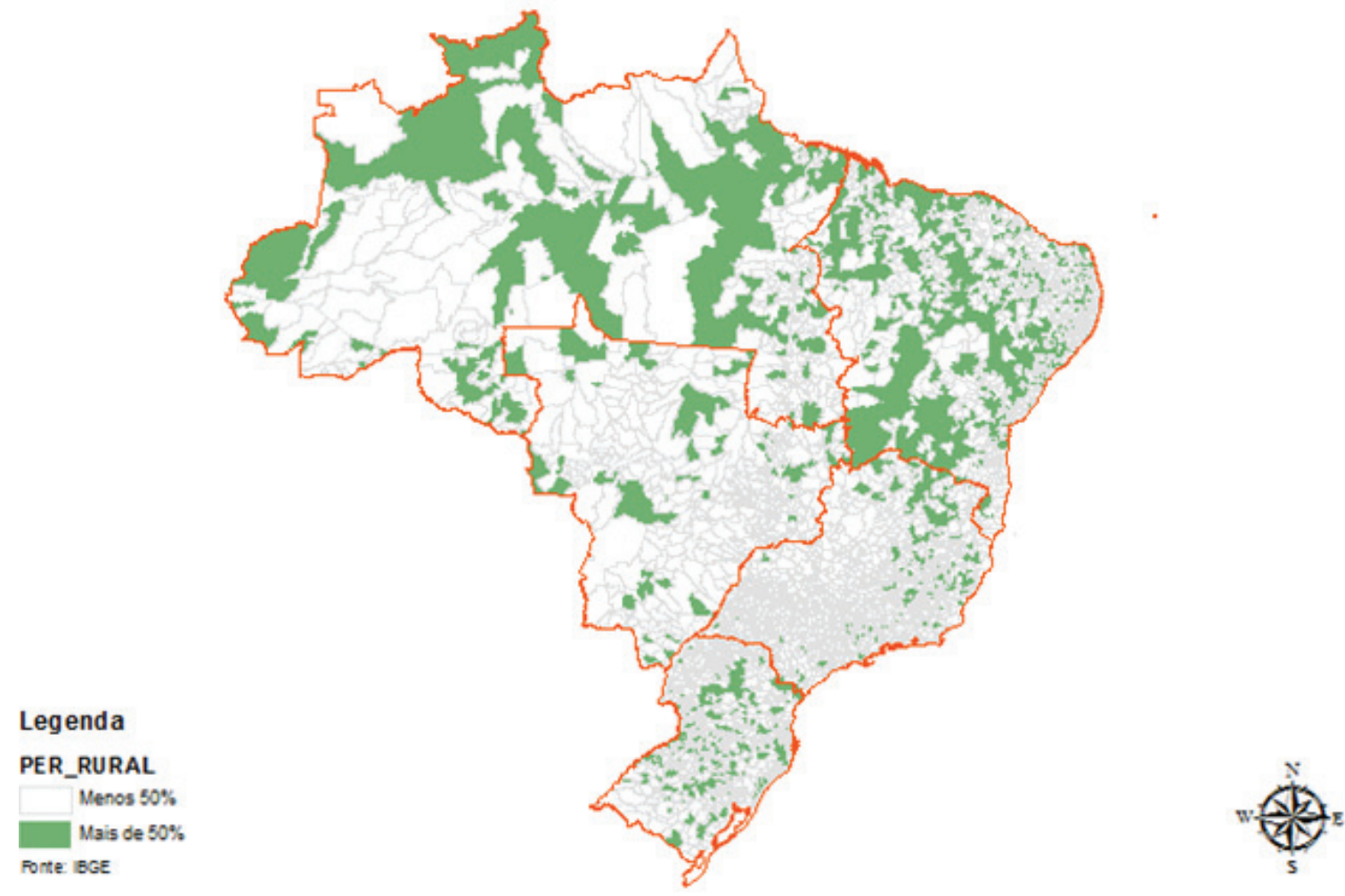

Fonte: IBGE, Censo Demográfico 2010. Elaboração: OBTEIA

O estado brasileiro que possui maior percentual de população residente em área rural é o Maranhão, com 36,92\%. O Distrito Federal apresenta o menor percentual, com 3,42\%. Quanto ao município mais rural, tem-se o Careiro da Várzea-AM, cuja população rural chega a 95,82\%3.

Para o IBGE a população rural é aquela residente em situação de domicílio rural. E o que viria a ser "Situação de domicílio rural"? Baseia-se, pois, em um não conceito, ou seja, é o que não é urbano. Para melhor esclarecer, as notas metodológicas da PNAD (2011) dizem que:

Como situação urbana, consideram-se as áreas correspondentes às cidades (sedes municipais), às vilas (sedes distritais) ou às áreas urbanas isoladas. A situação rural abrange toda a área situada fora desses limites.

É com base nessa lacuna conceitual que são conduzidos os censos, as PNADs e tantas outras pesquisas no Brasil. Para fragilizar ainda mais, a delimitação do urbano é definida pelas Câmaras Municipais, independente de qualquer outra consideração. Por exclusão, as demais áreas são consideradas rurais ${ }^{4}$. Apesar de a terminologia rural ter sido utilizada nos resultados do OBTEIA, entende-se que o conceito de ruralidade é muito mais amplo e complexo que os apresentados. $\mathrm{O}$ rural é mais que um espaço de produção agrícola, é também local de vida e moradia. 
Para Miranda e Silva ${ }^{5}$ a ruralidade refere-se à forma como se organiza a vida social, considerando o acesso aos recursos naturais, aos bens e serviços, e aí se incluem os serviços de saúde; refere-se à composição da sociedade rural em classes e categorias sociais e aos valores culturais.

Enquanto que, na PNSICF, a população rural é definida como:

[...] trabalhadores rurais assalariados e temporários que residam ou não no campo; trabalhadores rurais assentados e acampados; comunidade de quilombolas; populações que habitam ou usam reservas extrativistas; populações ribeirinhas; populações atingidas por barragens; outras comunidades tradicionais; dentre outros"2 (p. 22).

Outro aspecto que deve ser considerado é a população residente em domicílio rural do sexo feminino, que apresentou percentuais inferiores aos da população masculina nos censos apresentados na série histórica 1970-2010 em todas as grandes regiões, contrariando o perfil urbano brasileiro (Figura 2).

Figura 02: Processo da masculinização rural

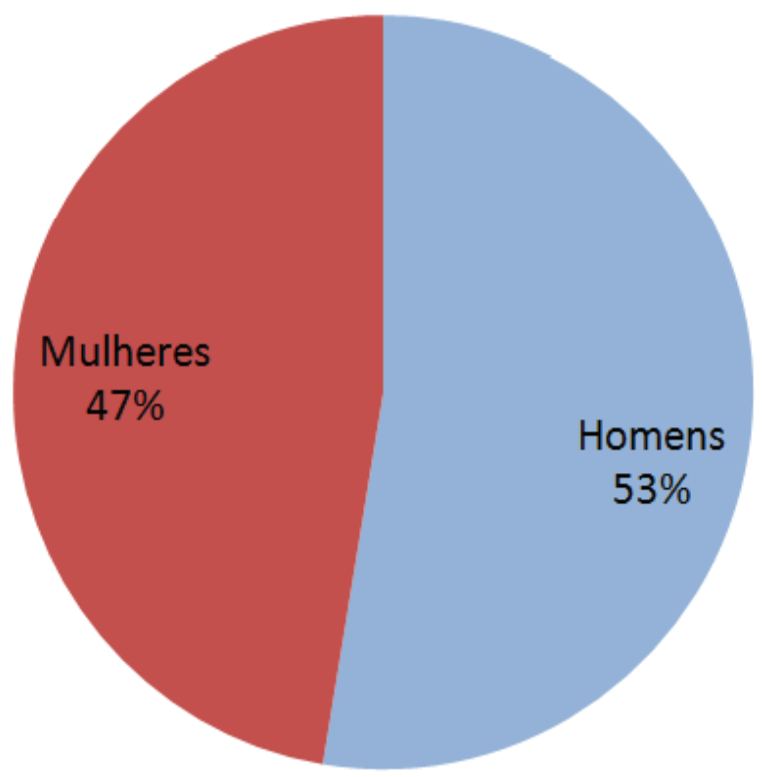

FONTE: IBGE, Censo Demográfico 2010. Elaboração: OBTEIA

O Brasil rural vem apresentando o contínuo êxodo rural, principalmente das filhas dos agricultores familiares que buscam a vida no meio urbano objetivando outras profissões. A tal fenômeno dáse o nome de masculinização do meio rural ${ }^{6}$, definido por Rioja ${ }^{7}$ como sendo um desequilíbrio demográfico caracterizado pelo déficit de mulheres em relação à proporção que deveria existir, naturalmente, entre os sexos. Este desequilíbrio aponta para a necessidade de políticas públicas específicas, visando a alterar esse quadro.

Um estudo realizado no Rio Grande do Sul por Froehlich ${ }^{8}$ confirmou a consolidação da 
masculinização rural naquela UF, especialmente, na faixa etária de 25 a 29 anos. Além disso, verificou a ocorrência do envelhecimento rural. Aliás, a faixa etária 60 ou mais foi a única, nesse estudo, que apresentou aumento populacional. A permanência da população idosa tem como fator motivador a aposentadoria rural ${ }^{8}$.

Essa predominância masculina, considerando as populações rurais por gênero do censo de 2010, apresentou significância estatística ao nível de 0,05, para todas as Unidades Federativas.

Percebe-se claramente que, ao analisarmos a distribuição da população residente em domicílio rural por sexo, segundo os grupos de idade, o Brasil rural exibe uma verdadeira "pirâmide", exceto na faixa de 0 a 9 anos, o que mostra a diminuição da presença dos jovens, dos adultos em idade produtiva e dos idosos no campo.

Figura 03: Distribuição da população residente em domicílio rural por sexo, segundo os grupos de idade (Brasil-2010).

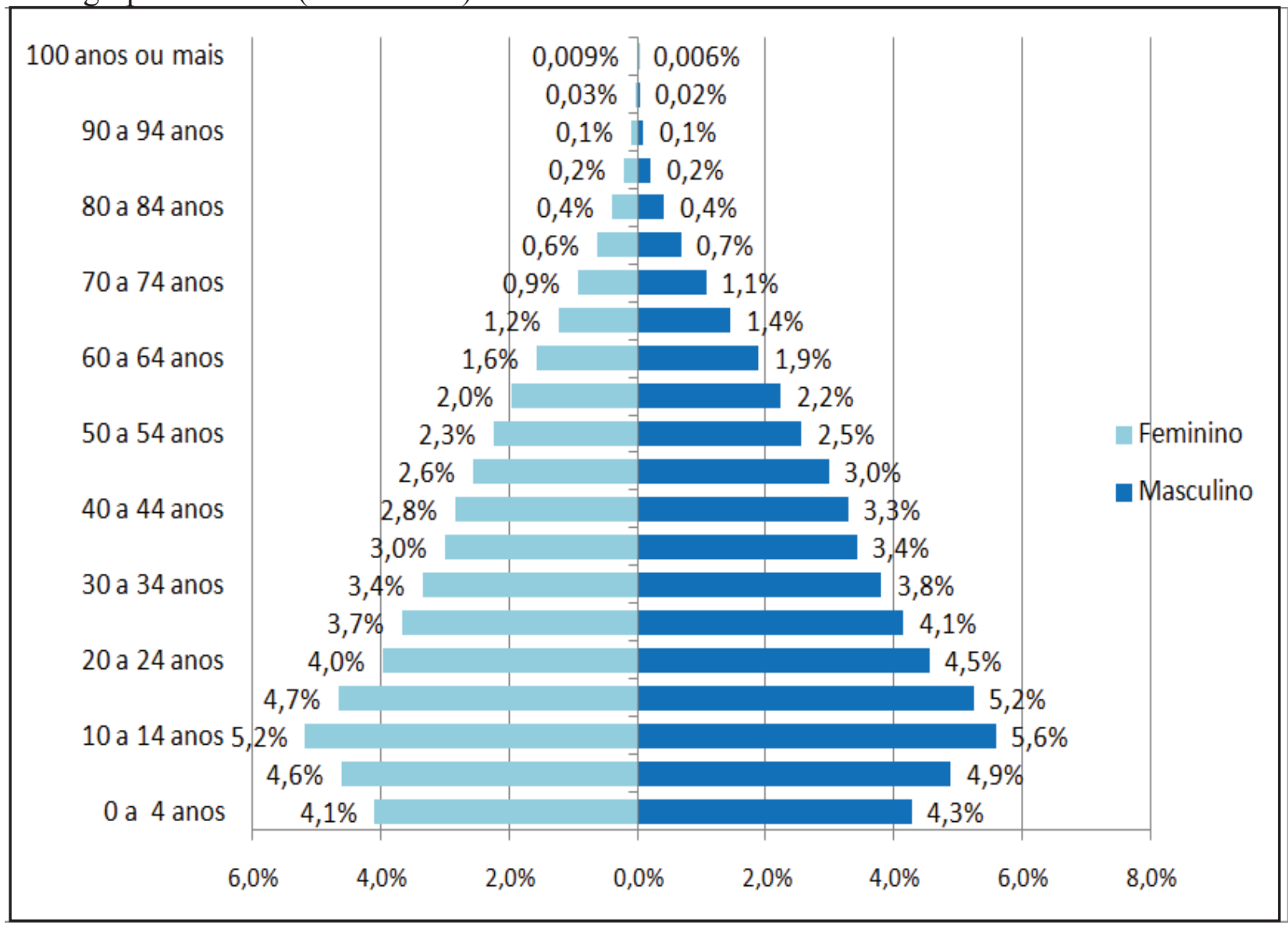

FONTE: IBGE, Censo Demográfico 2010. Elaboração: OBTEIA.

As necessidades de saúde dessas populações são historicamente maiores do que as das populações urbanas. Para fazermos uma aproximação ao tema podemos usar o exemplo do saneamento, dívida histórica do Estado com a população brasileira.

Fazendo uma análise desagregada dos dados da PNAD $2011^{9}$ por situação censitária Rural, 
segundo a Unidade Federativa, das variáveis que refletem as condições de infraestrutura domiciliar tem-se que, em média, $48,4 \% \mathrm{IC}_{95 \%}(43,9-53,8)$ dos domicílios rurais apresentam água canalizada. No Espírito Santo, tem-se 72,7\% de domicílios rurais com água canalizada (Figura 04).

Entretanto, vale ressaltar que ter água canalizada não implica dizer ter água de qualidade, mas o fato de já se contar com água dentro do domicílio é um grande facilitador das ações de higiene, por exemplo.

Figura 04: Presença de água encanada na residência, Brasil, 2010

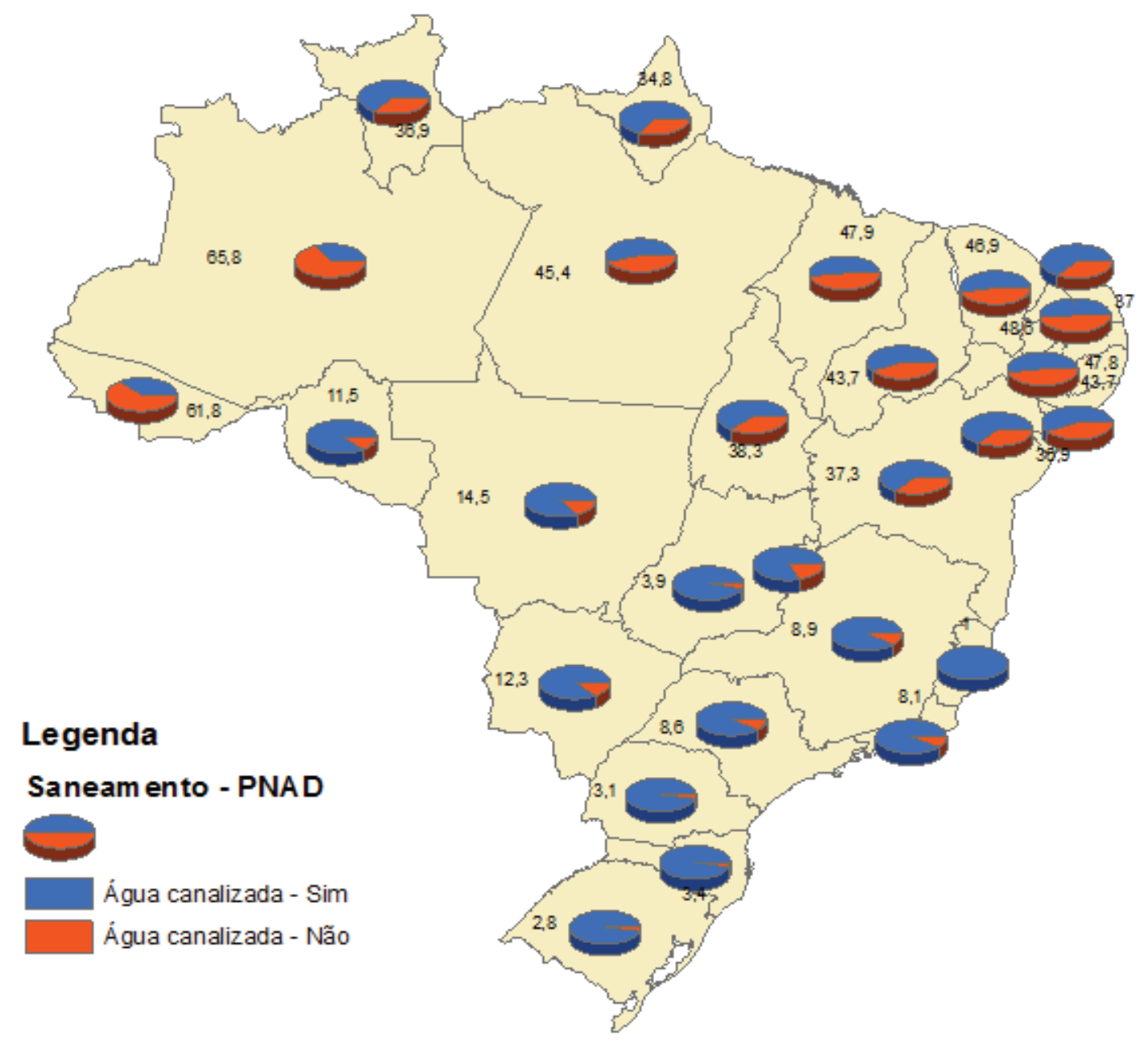

FONTE: IBGE, Censo Demográfico 2010.

Observou-se que o Sistema de Informação sobre Mortalidade (SIM) e o Sistema de Informação sobre Nascidos Vivos (SINASC) não identificam o local da residência dessa população. Isso representa uma limitação na construção de indicadores importantes como as taxas de mortalidade. Embora os Sistemas de Informações em Saúde (SIS) tenham avançado muito no Brasil, é fundamental identificar e reconhecer essas populações para se avançar na implementação de políticas públicas considerando as suas reais necessidades. 
b) Quais as interfaces das politicas intra e intersetoriais com a PNSIPCF?

Com o propósito de responder a essa pergunta foi realizado um exercício analítico que nasceu de uma demanda do Comitê Gestor do OBTEIA, no sentido de identificar as interfaces de políticas e ações intra e intersetoriais do Estado com a PNSIPCF. A princípio, seriam analisados os planos municipais e estaduais de saúde, porém, dada a impossibilidade de consultá-los, devido ao grande número de planos existentes no país, bem como que esse observatório não dispunha de recursos suficientes para a consulta, optou-se pela análise de políticas.

Assim, essa análise visou a identificar as interfaces da PNSIPCF com algumas políticas intra e intersetoriais das áreas da saúde, desenvolvimento social e meio ambiente. É importante ressaltar que não buscamos nesta investigação explorar todas as possibilidades analíticas das políticas aqui demarcadas e escolhidas, pois as compreendemos que, em sua singularidade, cada uma delas nos remete a desafios típicos em cada realidade a que estão inseridas e, também, porque são interpretadas, intercedidas e operacionalizadas por instituições, órgãos e pessoas que estão em cada contexto específico.

Em termos metodológicos, utilizou-se a Pesquisa Documental. Os documentos foram selecionados de acordo com a sua relevância para o tema abordado; por sua confiabilidade, por se tratarem de documentos oficiais elaborados pelo governo Federal; e pela temporalidade, por serem documentos recentes.

Para fins de apreensão do material documental utilizaram-se os sítios das Instituições Governamentais, tais como: do Ministério da Saúde, do Ministério de Desenvolvimento Social e Combate à Fome, entre outros. Além disso, foram realizadas visitas à sede do próprio Ministério da Saúde em Brasília para a busca de Políticas e Planos impressos a fim de agregá-los os materiais digitais já existentes no banco de dados deste estudo.

Dessa forma, os documentos utilizados para análise foram: 
Quadro 01: Relação Nominal dos Documentos por área

\begin{tabular}{|c|c|}
\hline ÁREA & DOCUMENTO \\
\hline \multirow{14}{*}{ SAÚDE } & 1. Política Nacional de Atenção Básica (PNAB) \\
\hline & 2. Plano Nacional de Saúde - 2012/2015 (PNS) \\
\hline & 3. Política Nacional de Práticas Integrativas e Complementares no SUS (PNPIC) \\
\hline & 4. Política Nacional de Atenção Integral à Saúde do Homem (PNAISH) \\
\hline & 5. Política Nacional da Pessoa Idosa (PNPI) \\
\hline & 6. Política Nacional de Atenção Integral à Saúde da Mulher (PNAISM) \\
\hline & 7. Política Nacional de Saúde Integral da População Negra (PNSIPN) \\
\hline & $\begin{array}{l}\text { 8. Portaria GM/MS 2.728/2009 - Rede Nacional de Atenção Integral à Saúde do } \\
\text { Trabalhador (RENAST) }\end{array}$ \\
\hline & 9. Decreto $\mathrm{n}^{0} 7.508 / 2011$ - Regulamentação da Lei no 8.080/90 \\
\hline & 10. Contrato Organizativo de Ação Pública (COAP) \\
\hline & $\begin{array}{l}\text { 11. Política Nacional de Saúde Integral do Trabalhador e da Trabalhadora } \\
\text { (PNSITT) }\end{array}$ \\
\hline & 12. Política Nacional de Educação Permanente em Saúde (PNEPS) \\
\hline & 13. Política Nacional de Educação Popular em Saúde no SUS (PNEPS-SUS) \\
\hline & 14. Diretrizes da $1^{\text {a }}$ Conferência Nacional de Saúde Ambiental ( $\left.\mathbf{1}^{\mathrm{a}} \mathbf{C N S A}\right)$ \\
\hline \multirow{4}{*}{$\begin{array}{l}\text { DESENVOLVIMENTO } \\
\text { SOCIAL }\end{array}$} & 15. Plano Plurianual 2012/2015 - (PPA - 2012/2015) \\
\hline & 16. Plano "Brasil sem Miséria" \\
\hline & 17. Política Nacional de Alimentação e Nutrição (PNAN) \\
\hline & 18. Política Nacional de Promoção da Igualdade Racial (PNPIR) \\
\hline \multirow{4}{*}{ MEIO AMBIENTE } & 19. Política Nacional de Agroecologia e Produção Orgânica (PNAPO). \\
\hline & 20. Relatório da Conferência de Desenvolvimento Rural e Sustentável (CDRS) \\
\hline & 21. Territórios da Cidadania (TC) \\
\hline & 22. Política Nacional de Saneamento \\
\hline
\end{tabular}

FONTE: Dados produzidos pelo próprio estudo

Realizou-se a análise dos documentos com vistas ao objetivo e diante das seguintes questões: Qual (is) objetivo (s), princípio ( $s$ ) e diretriz (es) existe $(m)$ nos documentos que se referem às populações do campo e da floresta? E, qual (is) ação (ões), meta (s) e estratégias (es) esses documentos apontam para as populações do campo e da floresta?

Assim, procedeu-se de uma intepretação coerente à luz dos referidos questionamentos, bem como sua interface com os eixos propostos no Plano Operativo da PNSIPCF 2012/2015² que são: a) Eixo 01: Acesso das populações do campo e da floresta na atenção à saúde; b) Eixo 02: Ações de promoção e vigilância em saúde às populações do campo e da floresta; c) Eixo 03: Educação 
permanente e educação popular em saúde com foco nas populações do campo e da floresta; e d) Eixo 04: Monitoramento e avaliação do acesso às ações e serviços às populações do campo e da floresta.

Para a organização e processamento analítico do material documental utilizamos quadrossínteses com as principais contribuições de cada política em interface com a PNSIPCF. Lembramos que cada política foi analisada partindo da interface relativa a cada um dos quatro eixos previstos na PNSIPCF relacionados ao Plano Operativo do período 2012/2015.

Dessa forma, do material documental emergiram três categorias que constituíram a rede interpretativa: a) Objetivos, Princípios e Diretrizes das Políticas Públicas Intrasetoriais e Intersetoriais para as populações do campo e da floresta; b) Ações, Metas e Estratégias contidas nas Políticas Públicas Intrasetoriais e Intersetoriais para as populações do campo e da floresta; e c) Políticas Públicas Intrasetoriais e Intersetoriais sem objetivos, princípios, diretrizes, ações, metas e estratégias direcionados para as populações do campo e da floresta.

Salientamos que o detalhamento dos achados desta análise será objeto de outro manuscrito, mas, a partir desses resultados, podemos fazer alguns destaques, como as interfaces identificadas entre o Plano Nacional de Saúde ${ }^{10}$ e no Plano Plurianual $\left(2012\right.$ - 2015) ${ }^{11}$.

Também foram identificados importantes avanços, em termos de ações programadas pelo governo Federal, direcionadas para a saúde das populações do campo e da floresta, como:

a) Disponibilização de recursos complementares para municípios com dificuldades de atração e fixação de profissionais;

b) Cadastramento e vinculação de parteiras tradicionais;

c) Acesso aos serviços de saúde por meio da ESF: custeio para implantação de novas EqESF Ribeirinhos e Fluviais;

Ao lado disso, indagamos: o que é possível extrair da análise de políticas intrasetoriais e intersetoriais para o fortalecimento e melhorias em saúde das populações do campo e da floresta? Até onde elas nos munem de elementos e dimensões para se avaliar o que chega até os territórios? Observa-se, portanto, ainda certa "invisibilidade" da população em foco (campo, floresta e água) no que tange ao desenvolvimento e operacionalização de políticas públicas.

A análise desses documentos oficiais nos mostra que ainda há um distanciamento significativo entre o que o Estado brasileiro formula para essas populações, principalmente se dialogarmos com 
o conceito ampliado de saúde e com a determinação social do processo saúde-doença. Ressalta-se a necessidade de debater de forma mais intensiva o processo de formulação e de implementação de políticas públicas para essas populações, tendo em vista que no SUS - que tem mais de 20 anos e tem o compromisso de garantir a universalidade do acesso, a integralidade da atenção e a equidade - ainda é tímida a implantação de serviços primários de saúde, Unidades Básicas para Ribeirinhos e Fluviais, por exemplo.

Nesta sessão, apresentamos resultados preliminares de informações produzidas pelo OBTEIA a partir de dados obtidos de bancos de dados oficiais e de documentos institucionais. Essas análises foram realizadas de forma coletiva envolvendo epidemiologistas, pesquisadores qualitativos, movimentos sociais, acadêmicos, entre outros.

Para tanto, essa elaboração e análise se deu obedecendo ao seguinte fluxo: captura de dados; em seguida, foi escrita uma primeira versão que passou pela análise de profissionais de distintas áreas; depois, foi apresentada para um grupo maior (comitê gestor, equipe executiva e a Teia de Saberes e Práticas), em oficina, para sugestões, críticas e ajustes; a seguir, foram acolhidas tais sugestões, críticas e ajustes e, novamente, o trabalho foi apresentado para esse mesmo grupo para validação final e sugestão de forma de tradução para os diversos públicos.

\section{5) Que metodologias participativas podem ser implementadas neste observatório a fim de possibilitar o diálogo entre movimentos sociais, pesquisadores engajados e gestores/trabalhadores do SUS?}

O OBTEIA criou uma estrutura diferente da maioria dos observatórios acadêmicos. Em todos os seus níveis de organização, do comitê gestor ao grupo executivo e à Teia de Saberes e Práticas, conta-se com a participação de acadêmicos, representantes de movimentos sociais e do SUS. Em todas as instâncias são feitos debates teóricos e políticos com implicações práticas. Essa forma de existir reflete-se nas oficinas, e por meio de todos esses espaços as decisões são tomadas e implementadas. O próximo desafio para o OBTEIA é desenvolver pesquisas de campo que reflitam essa filosofia.

Métodos como a pesquisa participante, pesquisa-ação, educação popular, etnografia ativista, extensão popular, pesquisa militante, entre outros, são os termos, as formas e as consignas para expressar o anseio e o compromisso de pesquisadores, professores, profissionais e integrantes de movimentos sociais em contribuir efetivamente para a transformação de uma realidade social marcadamente desigual. Ao longo da história latinoamericana, este anseio esteve presente nos espaços de educação formais, não formais e informais e, mesmo que minoritariamente, no processo de construção de nossas Universidades, gerando contribuições teóricas e práticas que propiciaram a compreensão de conjunturas complexas e a produção de conhecimentos e ações significativas para a transformação social ${ }^{12}$. 
Há a necessidade de se construir novos métodos, ou os métodos citados acima são suficientes para o desafio colocado para as pesquisas de campo do OBTEIA? Essa pergunta irá orientar os debates e os novos desdobramentos da pesquisa no OBTEIA nos anos de 2014 e 2015.

\section{NOSSO APRENDIZADO NO DESENVOLVIMENTO DESTA EXPERIÊNCIA}

A criação e o desenvolvimento do OBTEIA colocaram-nos diante de três grandes desafios. O primeiro foi o de dar visibilidade a essas populações, ainda pouco visíveis nas suas necessidades de saúde e condições de vida pelas estatísticas oficiais e pelas políticas públicas. O segundo, e igualmente desafiante, foi inventar uma nova forma de se estruturar um Observatório, onde o "observado" também "observa" e vice versa. Aqui sujeito e objeto se alternam numa perspectiva dialética de construção de análises que induzam à ação, seja do Estado, seja dos próprios movimentos sociais. Para isso se efetivar plenamente, deparamo-nos com o terceiro desafio, que é o desenvolvimento e articulação de métodos de produção do conhecimento coerentes com essa proposta. A partir dessa plataforma queremos contribuir com um novo paradigma para se praticar a avaliação das políticas públicas. Esse relato é um dos primeiros passos nessa direção.

A sociedade tem demandado a elaboração e/ou monitoramento e avaliação de políticas públicas. Nesse sentido, implantar um Observatório é uma ação muito maior do que o investimento de recursos públicos para um tipo de registro e compilação de dados. É, também, a oportunidade de contribuir para a estruturação de outros processos avaliativos das políticas públicas, nesse caso, as de saúde.

Ele integra a participação ativa de distintos agentes sociais a fim de produzir e disponibilizar dados e informações para os mais variados públicos e que esses possam utilizar tais dados e informações para a produção de novos conhecimentos e práticas para a melhoria das condições de vida das populações foco do Observatório.

A experiência vivida na implantação do OBTEIA vem possibilitando o envolvimento e o reconhecimento político de distintos grupos e o significado dessa ferramenta como estratégia de fortalecimento e melhoria da produção de informações capazes de disparar ações e decisões, no campo das políticas públicas, para as populações do campo, da floresta e das águas.

\section{REFERÊNCIAS}

1. Brasil. Lei Orgânica da Saúde. Lei no 8.080, de 19 de setembro de 1990. Brasília, DF: Senado; 1988.

2. Brasil. Ministério da Saúde. Política Nacional de Saúde Integral das Populações do Campo e da Floresta. 1. ed. Brasília : Editora do Ministério da Saúde; 2013.

3. Instituto Brasileiro de Geografia e Estatística (IBGE). Censo Demográfico 2010 - Resultados 
do universo. Disponível em: http://www.ibge.gov.br. Acesso em: 20 ago. 2013.

4. Araújo TB. O Brasil rural contemporâneo: reafirmando a importância e a diversidade. VIII Fórum Internacional de Desenvolvimento Territorial.2013. Disponível em: http://iicaforumdrs.org. br/iica2011/adm/arquivosup/942c429efaa90586fb09dbce4181e9b9Tania\%20Bacelar\%20-\%20 VIII\%20F\%C3\%B3rum.pdf. Acesso em: 25 nov. 2013.

5. Miranda C, Silva H. Concepções da ruralidade contemporânea: as singularidades brasileiras Org. Brasília: IICA, 2013.

6. Stropasolas VL. Trabalho infantil no campo: do problema social ao objeto sociológico. Revista Latino-americana de Estudos do Trabalho 2012; 17(27):249-286.

7. Rioja LAM. et al. La población rural de España: de los desequilibrios a la sostenibilidad social. Barcelona: Fundación La Caixa, 2009. (Colección Estudios Sociales n. 27). Disponível em: $<$ http://www.laCaixa.es/ObraSocial>. Acesso em: 15 set. 2013.

8. Froehlich JM, Rauber CC, Carpes RH, Toebe M. Êxodo seletivo, masculinização e envelhecimento da população rural na região central do RS. Ciência Rural 2011; 41(9):1674-1680.

9. Pesquisa Nacional por Amostra de Domicílios 2011. Disponível em: http://www.sidra.ibge. gov.br/pnad/ Acesso em: 09 de set. 2013.

10. Brasil. Ministério da Saúde. Plano Nacional de Saúde 2012-2015. Brasília, Ministério da Saúde; 2011.

11. Brasil. Ministério do Planejamento, Orçamento e Gestão. Plano plurianual 2012-2015: projeto de lei. Brasília, MP; 2011.

12. Bringel B, Varella RVS. Pesquisa Militante e Produção de Conhecimentos: o enquadramento de uma perspectiva. Disponível em < http://netsal.iesp.uerj.br/images/diversos/Texto-base.pdf $>$. Acesso em 19 de maio de 2014. 